\section{Cureus}

Received 06/07/2018

Review began 06/27/2018

Review ended 10/01/2018

Published 10/09/2018

\section{(C) Copyright 2018}

Bliven et al. This is an open access article distributed under the terms of the Creative Commons Attribution License CC-BY 3.0., which permits unrestricted use, distribution, and reproduction in any medium, provided the original author and source are credited.

\title{
Evaluating a Change in Surgical Antibiotic Prophylaxis in Kidney Transplant Recipients
}

Katherine Bliven ${ }^{1}$, Karisa Snow ${ }^{1}$, Adrian Carlson ${ }^{1}$, Sarah Yeager ${ }^{1}$, Nicole Kenyon ${ }^{1}$, Lonnie Smith ${ }^{1}$, Crystal M. Truax ${ }^{1}$, Eryberto Martinez ${ }^{1}$, Jeffrey Campsen ${ }^{1}$

1. Surgery, University of Utah, Salt Lake City, USA

$\square$ Corresponding author: Jeffrey Campsen, jeffrey.campsen@hsc.utah.edu Disclosures can be found in Additional Information at the end of the article

\section{Abstract}

The purpose of this study was to retrospectively evaluate if a change in practice from January 2013 to August 2015 affected the rate of surgical-site infections following kidney transplantation at the single academic medical center. More patients were found to have a surgical-site infection when surgical antibiotics were only given intra-operatively despite a lower incidence of risk factors identified in the literature when compared to the cohort who received antibiotics intra-op and post-op for 24 hours.

Categories: Transplantation

Keywords: surgical wounds, human, kidney transplant, infection prophylaxis, antibiotic prophylaxis

\section{Introduction}

Kidney transplantation is a well-established and highly successful treatment for end-stage renal disease. In 2014, over 17,000 kidney transplants took place in the United States [1]. Despite its rate of success, multiple complications can arise from the transplant procedure. The rate of post-operative infections following a kidney transplant ranges from 1 to 56\%, with one of the most common infections being surgical-site infections, which occur in up to $11 \%$ of patients [2]. Although surgical-site infections rarely lead to graft loss, they can lead to significant morbidity and prolonged hospitalization [3]. Multiple risk factors have been identified that increase the risk of acquiring a surgical site infection in the kidney transplant population including body mass index (BMI) greater than 27, immunosuppression regimen, older age, diabetes, cold ischemic time of more than 30 hours, duration of surgical procedure longer than 200 minutes and delayed graft function [3-6]. Diabetes, coronary artery disease and peripheral vascular disease are also literature reported risk factors for surgical-site infections in this population [3-6].

The risk of surgical-site infections related to immunosuppression may be affected by the intensity of immunosuppression, the receipt of these medications prior to transplant and certain agents pose a higher risk. The use of immunosuppressive medications prior to transplant is also a risk factor for surgical-site infections in kidney transplant recipients. Patients who receive more intense immunosuppressive regimens will likely be at a greater risk of developing a surgical-site infection. Mycophenolate mofetil (MMF) and mammalian target of rapamycin (mTOR) inhibitors are commonly used in maintenance therapy following a kidney transplant and are independent risk factors for surgical-site infections [2]. In addition, corticosteroids and mTOR inhibitors delay wound healing in multiple studies [6]. 


\section{Cureus}

There currently is no consensus on the optimal perioperative prophylaxis regimen for renal transplant surgery [4, 7]. However, there is consensus that perioperative antibiotics are to be administered within 60 minutes of surgical incision and are not to last longer than 24 hours [2]. The American Society of Health-System Pharmacists (ASHP), the Infectious Diseases Society of America (IDSA), the Surgical Infection Society (SIS), and the Society for Healthcare Epidemiology of America (SHEA) jointly developed guidelines for antimicrobial prophylaxis in surgery. These joint guidelines have specific recommendations for kidney transplant surgery and state that cefazolin is the preferred antibiotic in this patient population (strength of evidence = A) [2]. The guidelines recommend that non-obese patients weighing less than $120 \mathrm{~kg}$ receive cefazolin $2 \mathrm{~g}$ IV within the one hour time frame and be re-dosed every four hours throughout surgery. The recommended dose of cefazolin is increased to $3 \mathrm{~g}$ IV in patients weighing greater than or equal to $120 \mathrm{~kg}$. Clindamycin or vancomycin in combination with gentamicin, aztreonam, or a fluoroquinolone are alternatives for penicillin-allergic patients (strength of evidence $=\mathrm{C}$ ) [2].

Surgical-site infections may lead to higher treatment cost, possible re-admissions, increased antibiotic use, possible surgical procedures, and increased risk of Clostridium difficile [4]. Less antibiotic exposure presents many advantages including reduced potential for resistant organisms, decreased health care costs and decreased potential for toxicity [4].

Prior to April 2014, the standard practice at our institution was to administer cefazolin $1 \mathrm{~g}$ IV intra-operatively followed by cefazolin $1 \mathrm{~g}$ IV every eight hours for 24 hours, post-operatively. In April 2014, the protocol changed to administer a single dose of cefazolin $1 \mathrm{~g}$ IV intraoperatively, and to no longer administer surgical prophylaxis post-operatively. If the surgical procedure lasts longer than four hours, both protocols required that the patient be re-dosed with the appropriate antibiotic(s) intra-operatively. Patients with a penicillin allergy were administered an alternative agent. The choice of alternative antibiotic in penicillin-allergic patients was not standardized at the institution and instead, antibiotic choice was at the discretion of the anesthesiologist or surgeon. Regardless of the antibiotic chosen, the duration of surgical antibiotic prophylaxis remained the same in both protocols.

The purpose of this study was to retrospectively evaluate if the change in practice affected the rate and classification of surgical-site infections following kidney transplantation at this single academic medical center.

\section{Materials And Methods}

The primary objective of this study was to determine if the change in surgical antibiotic prophylaxis in kidney transplant patients affected the rate and classification of surgical-site infections in this patient population, using the Centers for Disease Control (CDC) National Nosocomial Infection Surveillance System (NNIS) definition for surgical-site infections (Table 1) [8]. The secondary objectives of this study were to evaluate the effect of BMI and immunosuppression on the rate of surgical-site infections in kidney transplant recipients.

\section{Classification of surgical- site infections \\ Description \\ 1. Infection occurs within 30 days after the operation}

AND

\section{And requires one of the following}

- Purulent drainage, with or without laboratory confirmation, from the superficial incision 


\section{Cureus}

\begin{tabular}{|c|c|c|}
\hline $\begin{array}{l}\text { Superficial } \\
\text { incisional } \\
\text { surgical-site } \\
\text { infection (SSI) }\end{array}$ & $\begin{array}{l}\text { 2. Infection involves only skin or } \\
\text { subcutaneous tissue of the } \\
\text { incision } \\
\text { Do not report the following conditions as } \\
\text { surgical-site infection: } \\
\text { - Stitch abscess (minimal } \\
\text { inflammation and discharge } \\
\text { confined to the points of suture } \\
\text { penetration) } \\
\text { - Incisional SSI that extends into } \\
\text { the fascial and muscle layers } \\
\text { (see deep incisional SSI) }\end{array}$ & $\begin{array}{l}\text { - Purulent drainage, with or without laboratory } \\
\text { confirmation, from the superficial incision } \\
\text { - Organisms isolated from an aseptically obtained } \\
\text { culture of fluid or tissue from the superficial incision } \\
\text { - At least one of the following signs or symptoms of } \\
\text { infection: } \\
\text { ○ Pain or tenderness, localized swelling, } \\
\text { redness, or heat and superficial incision is } \\
\text { deliberately opened by surgeon, unless } \\
\text { incision is culture-negative } \\
\text { - Diagnosis of superficial incisional surgical-site } \\
\text { infection by the surgeon or attending physician. }\end{array}$ \\
\hline $\begin{array}{l}\text { Deep } \\
\text { incisional } \\
\text { surgical-site } \\
\text { infection }\end{array}$ & $\begin{array}{l}\text { 1. Infection occurs within } 30 \text { days } \\
\text { after the operation } \\
\text { AND } \\
\text { 2. Infection involves deep soft } \\
\text { tissues (e.g., fascial and muscle } \\
\text { layers) of the incision } \\
\text { Notes: } \\
\text { - Report infection that involves } \\
\text { both superficial and deep } \\
\text { incision sites as deep incisional } \\
\text { surgical-site infection } \\
\text { - Report an organ/space surgical- } \\
\text { site infection that drains } \\
\text { through the incision as a deep } \\
\text { incisional surgical-site infection }\end{array}$ & $\begin{array}{l}\text { - Purulent drainage from the deep incision but not } \\
\text { from the organ/space component of the surgical site } \\
\text { A deep incision spontaneously dehisces or is } \\
\text { deliberately opened by a surgeon when the patient } \\
\text { has at least one of the following signs or symptoms: } \\
\text { fever }\left(>38^{\circ} \mathrm{C}\right) \text {, localized pain, or tenderness, unless } \\
\text { site is culture-negative } \\
\text { - An abscess or other evidence of infection involving } \\
\text { the deep incision is found on direct examination, } \\
\text { during reoperation, or by histopathologic or } \\
\text { radiologic examination } \\
\text { - Diagnosis of a deep incisional surgical-site infection } \\
\text { by a surgeon or attending physician }\end{array}$ \\
\hline $\begin{array}{l}\text { Organ space } \\
\text { surgical-site } \\
\text { infection }\end{array}$ & $\begin{array}{l}\text { 1. Infection occurs within } 30 \text { days } \\
\text { after the operation } \\
\text { AND } \\
\text { 2. Infection involves any part of } \\
\text { the anatomy (e.g., organs or } \\
\text { spaces), other than the incision, } \\
\text { which was opened or } \\
\text { manipulated during an } \\
\text { operation }\end{array}$ & $\begin{array}{l}\text { - Purulent drainage from a drain that is placed through } \\
\text { a stab wound } \ddagger \text { into the organ/space } \\
\text { - Organisms isolated from an aseptically obtained } \\
\text { culture of fluid or tissue in the organ/space } \\
\text { - An abscess or other evidence of infection involving } \\
\text { the organ/space that is found on direct examination, } \\
\text { during reoperation, or by histopathologic or } \\
\text { radiologic examination } \\
\text { - Diagnosis of an organ/space surgical-site infection by } \\
\text { a surgeon or attending physician }\end{array}$ \\
\hline
\end{tabular}




\section{Cureus}

\section{TABLE 1: CDC NNIS definition of a surgical-site infection.}

‡ If the area around a stab wound becomes infected, it is not a surgical-site infection. It is considered a skin or soft tissue infection, depending on its depth.

CDC: Centers for Disease Control; NNIS: National Nosocomial Infection Surveillance System.

This study was a retrospective review of an observational cohort of patients who received a kidney transplant at a single academic medical center. A senior researcher reviewed all patients for surgical-site infections. Two independent researchers did all chart reviews manually. A third reviewer was available to clarify any questions or discrepancies found.

All recipients of a kidney transplant alone at the institution from January 1, 2013 to August 31, 2015 were eligible for inclusion. All recipients of any other organ at the same time as kidney transplant were excluded. Patients were divided into two groups: the Continuance group and the One-and-Done group. The Continuance group included 50 patients who received the historical surgical prophylaxis protocol of antibiotics given intra-operatively and continued for 24 hours post-operatively. The One-and-Done group included 50 patients who received one dose of antibiotics given intra-operatively only.

A power calculation indicated that over 400 patients were required in each group to detect a significant difference (assuming $11 \%$ incidence of surgical-site infection and a $5 \%$ decrease). It was not possible to achieve a study population of this size at the single academic medical center within a reasonable time frame, as this center averages approximately 80-100 kidney transplants annually. Rather, the investigators sought to look at trends in the data available within the institution.

\section{Results}

The baseline characteristics of all patients included in this study are presented in Table 2. Most patients were male, the average age was 49 years (SD+18.8 years), most patients received tacrolimus, mycophenolate and prednisone for maintenance immunosuppression and there was a similar number of deceased-donor kidney transplants in each group. There was a higher use of antibody induction (Continuance, $n=32$ vs One-and-Done, $n=24$ ), incidence of delayed graft function (Continuance, $\mathrm{n}=2$ vs One-and-Done, $\mathrm{n}=0$ ), and more patients with a BMI greater than 27 (Continuance, $\mathrm{n}=30$ vs One-and-Done, $\mathrm{n}=20$ ) in the Continuance group. At the time of transplant, diabetes (Continuance, $n=16$ vs One-and-Done, $n=11$ ), coronary artery disease (Continuance, $\mathrm{n}=9$ vs One-and-Done, $\mathrm{n}=6$ ) and use of immunosuppression (Continuance, $\mathrm{n}=10$ vs One-and-Done, $\mathrm{n}=5$ ) were also more common in the Continuance group. Overall, there were more literature reported risk factors present in the Continuance group compared to One-and-Done group.

\begin{tabular}{l|l|l}
\hline & Continuance $(\mathbf{n}=\mathbf{5 0})$ & One-and-Do \\
\hline Age, average year (range year) & $46.7(24-73)$ & $47.0(22-73)$ \\
Male & $58 \%(n=29)$ & $68 \%(n=34)$
\end{tabular}

Etiology of ESRD 


\section{Cureus}

- Alports

$$
8 \%(n=4)
$$

$2 \%(n=1)$

- Chronic glomerulonephritis

$$
24 \%(n=12)
$$

$16 \%(n=8)$

- Diabetes

$$
22 \%(n=11)
$$

$16 \%(n=8)$

- Drug toxicity

$$
10 \%(n=5) \quad 6 \%(n=3)
$$

- Hypertension

$16 \%(n=8)$

$24 \%(n=12)$

- Obstructive nephropathy

$8 \%(n=4)$

$6 \%(n=3)$

- Other

$12 \%(n=6)$

$16 \%(n=8)$

- Polycystic kidney disease

$16 \%(n=8)$

$10 \%(n=5)$

- Retransplant

$20 \%(n=10)$

$14 \%(n=7)$

- Reflux nephropathy

$8 \%(n=4) \quad 12 \%(n=6)$

- Renal dysplasia

- Unknown

$\mathrm{BMI}>27$

$60 \%(n=30)$

Pre-transplant

- Diabetes

- Coronary artery disease

$18 \%(n=9)$

- Peripheral vascular disease

- Immunosuppression

$40 \%(n=20)$

$12 \%(n=6)$

$4 \%(n=2)$

$4 \%(n=2)$

$2 \%(n=1)$

$10 \%(n=5)$ 


\section{Cureus}

Deceased donor transplant

Living donor transplant

Antibody induction

- Rabbit antithymocyte globulin

$36 \%(n=18)$

$28 \%(n=9)$

- None

CIT $>30$ hours

Duration of operation $>200$ minutes

Delayed graft function

- Alemtuzumab

$4 \%(n=2)$

$$
\begin{array}{ll}
60 \%(n=30) & 60 \%(n=30) \\
40 \%(n=40) & 40 \%(n=40)
\end{array}
$$

$$
36 \%(n=18) \quad 52 \%(n=26)
$$

$$
4 \%(n=2) \quad 22 \%(n=11)
$$

\section{TABLE 2: Baseline characteristics of patients $(n=100)$.}

ESRD: End-stage renal disease; GN: Glomerulonephritis; BMI: Body mass index; CIT: Cold ischemic time.

Within the first 30 days post-transplant, zero deep incisional and organ space surgical-site infections were found. Eight superficial incisional surgical-site infections were identified, two in the Continuance group and six in the One-and-Done group $(\mathrm{p}=0.16$, Fisher Exact Test). The overall infection rate in the Continuance group was $4 \%$ and $12 \%$ in the One-and-Done group. The risk factors present in patients with surgical-site infections are illustrated in Table 3. 


\section{Cureus}

Patient Age BMI > 27 Pre-TX DM Pre-TX CAD Pre-TX IS Induction Surgical prophylactic antibiotic

Continuance

$\begin{array}{llllllll}1 & 75 & \mathrm{Y} & \mathrm{Y} & \mathrm{Y} & \mathrm{N} & \text { ATG } & \text { Vanco } 1 \mathrm{~g} \\ 2 & 52 & \mathrm{Y} & \mathrm{Y} & \mathrm{Y} & \mathrm{N} & \text { ATG } & \text { CFZ } 1 \mathrm{~g}\end{array}$

One-and-Done

$\begin{array}{llllllll}1 & 63 & \mathrm{Y} & \mathrm{Y} & \mathrm{Y} & \mathrm{N} & \text { None } & \text { CFZ1g } \\ 2 & 73 & \mathrm{~N} & \mathrm{~N} & \mathrm{~N} & \mathrm{~N} & \text { Alemtuz } & \text { CFZ1g } \\ 3 & 36 & \mathrm{~N} & \mathrm{~N} & \mathrm{~N} & \mathrm{Y} & \text { ATG } & \text { Vanco } 1 \mathrm{~g} \\ 4 & 55 & \mathrm{Y} & \mathrm{N} & \mathrm{N} & \mathrm{N} & \text { None } & \text { Vanco } 1 \mathrm{~g} \\ 5 & 33 & \mathrm{~N} & \mathrm{~N} & \mathrm{~N} & \mathrm{~N} & \text { ATG } & \text { Clinda } 600 \mathrm{mg} \\ 6 & 30 & \mathrm{~N} & \mathrm{~N} & \mathrm{~N} & \mathrm{~N} & \text { None } & \text { CFZ } 1 \mathrm{~g}\end{array}$

\section{TABLE 3: Risk factors present in patients with surgical-site infections.}

Y: Risk factor present; N: Risk factor not present; BMI: Body mass index; DM: Diabetes; CAD: Coronary artery disease; IS: Immunosuppression; ATG: Rabbit anti-thymocyte globulin; Vanco: Vancomycin; CFZ: Cefazolin; Alemtuz: Alemtuzumab; Clinda: Clindamycin; TX: Transplant.

When analyzing the cohort of patients with surgical-site infections further, four of the eight patients with surgical-site infections received surgical antibiotic(s) that were not part of the standard cefazolin regimens. The previously stated overall infection rate in Continuance group was $4 \%(2 / 50)$, and increased to $20 \%(1 / 5)$ if a non-cefazolin regimen was used. The overall surgical-site infection rate was $12 \%(6 / 50)$ in One-and-Done group, and increased to $30 \%(3 / 10)$ in patients who received a non-cefazolin regimen.

The rate of surgical-site infections was also increased among those patients who received cefazolin $1 \mathrm{~g}$ compared to the overall surgical-site infection rate, in both cohorts. No surgicalsite infections occurred in patients who received $2 \mathrm{~g}$ or more of cefazolin intra-operatively (Continuance, $\mathrm{n}=25$ vs One-and-Done, $\mathrm{n}=18$ ) (Table 4). 


\section{Cureus}

\begin{tabular}{|c|c|c|}
\hline & Continuance & One-and-Done \\
\hline Overall infection rate & $4 \%(2 / 50)$ & $12 \%(6 / 50)$ \\
\hline Cefazolin $1 \mathrm{~g}$ intra-operatively & $5 \%(1 / 20)$ & $13.6 \%(3 / 22)$ \\
\hline Cefazolin $2 \mathrm{~g}$ or more intra-operatively & $0 \%(0 / 25)$ & $0 \%(0 / 18)$ \\
\hline Antibiotic other than cefazolin ${ }^{a, b}$ & $20 \%(1 / 5)$ & $30 \%(3 / 10)$ \\
\hline
\end{tabular}

\section{TABLE 4: Analysis of infection rates in different antibiotic regimens.}

a Vancomycin $1 \mathrm{~g}$ used once in Continuance group and six times in One-and-Done group.

b Single regimen used in 14/15 cases (cefoxitin $2 \mathrm{~g}+$ ertapenem $1 \mathrm{~g}$ used in one patient in One-and-Done group due to donor characteristics).

The choice of antibiotic prophylaxis among patients with surgical-site infections is presented in Table 3. This antibiotic choice was determined by the individual anesthesiologist or surgeon, and many patients who did not receive cefazolin, largely due to allergies, received a single dose of vancomycin $1 \mathrm{~g}$ and not dual therapy as recommended by the clinical practice guidelines for surgical prophylaxis.

Fifty percent of patients $(n=4)$ with a surgical-site infection had a BMI greater than 27 . The median BMI among patients without a surgical-site infection was 27.1 compared to 26.7 in those with a surgical-site infection.

The differences among the use of immunosuppression prior to transplant and immunosuppressive regimen used during transplant for the Continuance group and One-andDone are available in Table 2 . Over $60 \%$ of the patients with a surgical-site infection received antibody induction and 13\% were on immunosuppression prior to transplant. Eleven percent of patients in the Continuance group and $17 \%$ in the One-and-Done group received rabbit antithymocyte globulin for induction immunosuppression and developed a surgical-site infection. None of the patients who received alemtuzumab in the Continuance group versus $8.3 \%$ in the One-and-Done group developed a surgical-site infection. Maintenance immunosuppression with tacrolimus, mycophenolate and prednisone was similar between the two groups.

\section{Discussion}

We predicted that the Continuance group would have a higher incidence of surgical-site infections because more literature-reported risk factors were present at baseline. However, this is not what was observed in this small cohort. More patients were found to have a surgical-site infection when surgical antibiotics were only given intra-operatively (One-and-Done group), despite a lower incidence of risk factors identified in the literature when compared to the cohort who received antibiotics intra-op and post-op for 24 hours (Continuance group). It is possible that the patients included in this small cohort have additional risk factors that have not been reported in the literature.

Additionally, there was an increased incidence of surgical-site infections when a non-cefazolin based regimen was used. The majority of the non-cefazolin regimens used a single antibiotic, 


\section{Cureus}

such as vancomycin $1 \mathrm{~g}$ or clindamycin 600-900 mg. This suggests that the use of a single nonpenicillin regimen is insufficient to prevent surgical-site infections in this patient population and dual therapy should be used, as recommended by the guidelines (Table 5). All the results support the recommendations outlined in the clinical practice guidelines for antimicrobial prophylaxis in surgery.

\begin{tabular}{|l|l|l|}
\hline & Preferred antibiotic & True penicillin-allergy \\
\hline$<60 \mathrm{~kg}$ & Cefazolin $1.5 \mathrm{~g} \mathrm{IV}$ & Clindamycin $900 \mathrm{mg} \mathrm{IV}+$ levofloxacin $500 \mathrm{mg} \mathrm{IV}$ \\
$60-120 \mathrm{~kg}$ & Cefazolin $2 \mathrm{~g} \mathrm{IV}$ & Clindamycin $900 \mathrm{mg} \mathrm{IV}+$ levofloxacin $500 \mathrm{mg} \mathrm{IV}$ \\
$\geq 120 \mathrm{~kg}$ & Cefazolin $3 \mathrm{~g} \mathrm{IV}$ & Clindamycin $900 \mathrm{mg} \mathrm{IV}+$ levofloxacin $500 \mathrm{mg} \mathrm{IV}$ \\
\hline
\end{tabular}

\section{TABLE 5: Updated surgical antibiotic prophylaxis for kidney transplant recipients at single center.}

The incidence of surgical-site infections increased when cefazolin $1 \mathrm{~g}$ was used in either group. However, when cefazolin $2 \mathrm{~g}$ or more was used, as recommended by the guidelines, no surgicalsite infections occurred. This suggests that the increased incidence of surgical-site infections was more likely due to the cefazolin dose rather than the duration.

When evaluating the impact of BMI on surgical-site infections, we expected that patients with a higher BMI would acquire more surgical-site infections, because a BMI greater than 27 is a literature-reported risk factor. In our study, the median BMI for patients with surgical-site infections (26.7) was below the median BMI for patients without surgical-site infections (27.1). It is possible that this reflected the small sample size of our study. However, $50 \%$ of patients with a surgical-site infection had a BMI greater than 27. BMI greater than 27 has been validated as an independent risk factor for surgical-site infections [5]. Lynch et al. and Pham et al. demonstrated that overweight and obese patients are at higher risk for acquiring a surgical-site infection [6, 7]. Lynch et al. included 869 patients (351 with BMI > 30). Most surgical-site infections were superficial and significantly more surgical-site infections occurred in the obese group (non-obese, $10.5 \%$ vs obese $23.7 \%$; < 0.001) [7].

Patients with more intense immunosuppression and immunosuppression prior to transplant, were expected to acquire more surgical-site infections. Nearly $63 \%$ of the eight patients with surgical-site infections did receive antibody induction (Table 3). The maintenance regimens utilized were similar in both groups (i.e., tacrolimus, mycophenolate) and steroid continuance occurred in $100 \%$ of the patients in the Continuance group compared to $98 \%$ in the One-andDone group. In contrast, more patients in the Continuance group were on immunosuppressive medications prior to transplant compared to the One-and-Done group (20\% in the Continuance group versus $10 \%$ in the One-and-Done group). The skewed patient characteristics in this study are not enough to suggest that pre-transplant immunosuppression is not a risk factor for surgical-site infections. Our study does suggest that an inadequate dose of prophylactic antibiotics can put patients at an increased risk for such infections.

There are notable limitations of this study to address. First, this study was not powered to detect a statistically significant difference for surgical-site infection rates, because over 800 patients would need to be included, based on $11 \%$ surgical-site infection rate. The volume of kidney transplants at this single academic medical center could not support a population of this 
size in the given time frame. In addition, there may have been differences in the baseline characteristics of the two groups, as the two groups because they were not matched. Although this is a limitation, the result of fewer surgical-site infections found in the group with more risk factors suggests the unmatched baseline characteristics did not sway the results. The results presented may have limited external validity because this was a small cohort at an individual institution.

Strengths of this study include the patient sample - it was a true representation of the population at hand. Therefore, the results were truly applicable to the sole institution and exhibited strong internal validity. Another strength was the method of chart review; the use of two consistent reviewers with one referee minimized bias.

\section{Conclusions}

The results from this small retrospective review demonstrate that cefazolin $1 \mathrm{~g}$, administered intra-operatively only, is insufficient to prevent surgical-site infections in kidney transplant recipients. It also suggests that a single agent, such as clindamycin or vancomycin $1 \mathrm{~g}$ alone, does not protect kidney transplant recipients from surgical-site infections. Therefore, we implemented a change in our protocol in accordance with the clinical practice guidelines for antimicrobial prophylaxis in surgery. Cefazolin $2 \mathrm{~g}$ ( $3 \mathrm{~g}$ in patients greater than $120 \mathrm{~kg}$ ) is now the preferred regimen at out institution. Clindamycin in combination with levofloxacin is the preferred alternative regimen for use in penicillin-allergic patients. Less antibiotic exposure is advantageous because it can reduce the potential for resistant organisms, decrease health care costs and lessen the potential for toxicity. It also demonstrates the applicability of guidelinesupported change in transplant, rather than a continuation of what has been perceived to work in the past. After looking at our data, we have the opportunity to standardize the dose to minimize surgical-site infections in the future.

\section{Additional Information}

\section{Disclosures}

Human subjects: Consent was obtained by all participants in this study. Animal subjects: All authors have confirmed that this study did not involve animal subjects or tissue. Conflicts of interest: In compliance with the ICMJE uniform disclosure form, all authors declare the following: Payment/services info: All authors have declared that no financial support was received from any organization for the submitted work. Financial relationships: All authors have declared that they have no financial relationships at present or within the previous three years with any organizations that might have an interest in the submitted work. Other relationships: All authors have declared that there are no other relationships or activities that could appear to have influenced the submitted work.

\section{References}

1. Organ donation and transplantation statistics. (2015). Accessed: August 1, 2018: https://www.kidney.org/news/newsroom/factsheets/Organ-Donation-and-TransplantationStats.

2. Bratzler DW, Dellinger EP, Olsen KM, et al.: Clinical practice guidelines for antimicrobial prophylaxis in surgery. Am J Health-Syst Pharm. 2013, 70:195-283. 10.2146/ajhp120568

3. Capocasale E, De Vecchi E, Mazzoni M, et al.: Surgical site and early urinary tract infections in 1000 kidney transplants with antimicrobial perioperative prophylaxis. Transplan Proc. 2014, 46:3455-3458. 10.1016/j.transproceed.2014.07.071

4. Orlando G, Manzia T, Sorge R, et al.: One-shot versus multidose perioperative antibiotic prophylaxis after kidney transplantation: a randomized, controlled clinical trial. Surgery. 2015, 157:104-110. 10.1016/j.surg.2014.06.007

5. Wszola M, Kqiatkowski A, Ostaszewska A, et al.: Surgical site infections after kidney 


\section{Cureus}

transplantation-where do we stand now?. Transplantation. 2013, 95:878-882. 10.1097/TP.0b013e318281b953

6. Pham PT, Danovitch GM, Pham PC: Kidney transplantation in the obese transplant candidates: to transplant or not to transplant?. Semin Dial. 2013, 26:568-577.

10.1111/sdi.12109

7. Lynch RJ, Ranney DN, Sijie C, Lee DS, Samala N, Englesbe MJ: Obesity, surgical site infection, and outcome following renal transplantation. Ann Surg. 2009, 250:1014-1020. 10.1097/SLA.0b013e3181b4ee9a

8. Mangram AJ, Horan TC, Pearson ML, Silver LC, Jarvis WR: Guideline for prevention of surgical site infection, 1999. Am J Infect Control. 1999, 27:97-134. 10.1016/S0196-6553(99)70088-X 